\title{
Factors associated with elevated exhaled nitric oxide fraction in infants with recurrent respiratory symptoms
}

\author{
Anne Kotaniemi-Syrjänen, L. Pekka Malmberg, Kristiina Malmström, \\ Anna S. Pelkonen and Mika J. Mäkelä
}

ABSTRACT: Exhaled nitric oxide fraction ( $\mathrm{FeNO}$ ) has been proposed as a noninvasive marker of eosinophilic bronchial inflammation in active asthma, and supposed to reflect responsiveness to corticosteroid therapy. There are several factors influencing FeNO, and its role in early childhood respiratory disorders needs to be established.

Between 2004 and 2008, 444 children aged $<3$ yrs with recurrent lower respiratory tract symptoms were referred to a tertiary centre for further investigation. 136 full-term, steroid-free, infection-free infants, median age of 16.4 months (range 4.0-26.7 months), successfully underwent measurement of FeNO, lung function tests, and a dosimetric methacholine challenge test.

The median level of FeNO was $19.3 \mathrm{ppb}$ (interquartile range 12.3-26.9 ppb). Elevated FeNO ( $\geqslant 27 \mathrm{ppb}$, the highest quartile) was associated with maternal history of asthma (adjusted OR 3.2, $95 \% \mathrm{Cl} 1.3-8.1 ; p=0.012$ ), and increased airway responsiveness (the provocative dose of methacholine causing a $40 \%$ fall in maximal expiratory flow at functional residual capacity $\leqslant 0.30 \mathrm{mg}$ ) (adjusted OR 4.1, 95\% Cl 1.4-12.7; $\mathrm{p}=\mathbf{0 . 0 1 2}$ ). Atopy, blood eosinophilia and lung function were not associated with elevated FeNO.

In conclusion, maternal history of asthma, and increased airway responsiveness are associated with elevated FeNO in infants with recurrent lower respiratory tract symptoms.

KEYWORDS: Atopy, exhaled nitric oxide fraction, increased airway responsiveness, lung function tests, recurrent lower respiratory tract symptoms, wheezing

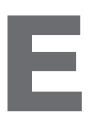
xhaled nitric oxide fraction $(F e N O)$ is a widely used noninvasive biomarker of active asthma in adults and school children

[1]. Elevated FeNO has been proposed as a marker of eosinophilic inflammation in bronchial mucosa, supposed to imply a favourable response to corticosteroid therapy [1]. In addition, increased airway responsiveness has been related to elevated levels of FeNO [2-4].

At pre-school age, children with probable asthma present with elevated FeNO [5]. However, the role of $F$ eNO in respiratory disorders of early childhood has not been established: wheezing illnesses in infancy are usually not associated with eosinophilic bronchial inflammation [6, 7], and although increased airway responsiveness may play a role in recurrent lower respiratory tract symptoms of early childhood [8], studies on the relationship of FeNO and increased airway responsiveness in infants are scarce [9]. In addition, there are several characteristics influencing FeNO values: i.e. methods used [10], the height of the child [2], the presence of atopic eczema [11, 12], skin-prick test reactivity $[2,3,7,12,13]$, acute respiratory symptoms [14-16], and tobacco smoke exposure [16-18].

The aims of the present study were to evaluate the relationship between FeNO and increased airway responsiveness, and to clarify whether there are any associations between elevated FeNO and anthropometrics and exposure to risk factors for respiratory morbidity in infants with recurrent lower respiratory tract symptoms. The initial findings for this study were presented, in part, at the European Respiratory Society Annual Congress in 2011 [19].
AFFILIATIONS

Dept of Allergology, Helsinki University Central Hospital, Helsinki, Finland.

\section{CORRESPONDENCE}

L. Pekka Malmberg

Skin and Allergy Hospital

P.0. Box 160

FIN-00029 HUS

Finland

E-mail: pekka.malmberg@hus.fi

Received:

Feb 032011

Accepted after revision:

May 312012

First published online:

June 272012 


\section{METHODS}

\section{Study subjects}

Between August 18, 2004 and November 26, 2008, a total of 444 children aged $<3$ yrs were referred to the Dept of Allergology at the Helsinki University Central Hospital (Helsinki, Finland) for investigation of recurrent lower respiratory tract symptoms (including wheeze, dry or productive cough, and/or shortness of breath). Of these children, 187 successfully underwent (in a respective order) measurement of $\mathrm{FeNO}$, lung function testing by whole body plethysmography and the rapid thoracic compression technique, and the dosimetric methacholine challenge test. The data of the remaining 257 cases were excluded because of missing $(n=220)$ or technically unacceptable $(n=37)$ measurements of FeNO, lung function, and/or airway responsiveness. In addition, pre-term (gestational age $<36$ weeks) infants, those on corticosteroid medication (during 1 month prior to testing), and those with any symptoms of acute respiratory infection (during 2 weeks prior to testing) were excluded, leaving 136 children for final analyses. Excluded children did not differ from included infants in any aspects of baseline characteristics. However, excluded children more often had abnormal results in baseline lung function measured by rapid thoracic compression technique $(p=0.021)$. Although, there were no differences in FeNO levels between included and excluded children $(\mathrm{p}=0.161)$.

All tests were performed as part of the recruitment phase of an intervention study on infant asthma, after informed consent was given from the parents to perform the tests. In addition, the parents were asked for further written consent to allow the use of the FeNO measurements, lung function and methacholinechallenge test results, skin-prick test (SPT) results, and related clinical data for research purposes. The intervention study, including measurement of: FeNO, performance of the baseline lung function tests, and the methacholine challenge test during the recruitment phase, was approved by the local ethics committee.

During the hospital visit, clinical data were collected with a standardised form designed for the intervention study by interviewing the parents, and by reviewing the medical records of the children. A small amount of blood, $<1 \%$ of the circulating blood volume, was collected for analysis of peripheral blood eosinophil count.

\section{Measurement of FeNO}

FeNO was assessed with a modification of online single-breath measurement [20]. During sedation, the babies spontaneously breathed room air through a mask covering the nose and the mouth, and a pneumotach attached to the mask. Rapid thoracoabdominal compression technique was applied to generate a forced expiration starting from end-inspiration. The expired air was led to a chemiluminescence analyser $\left(\mathrm{NIOX}_{\mathbb{B}}\right.$; Aerocrine, Solna, Sweden) via a shutter mechanism of the pneumotach and a three-way valve, and a dynamic resistor that restricted the expiratory flow to $50 \mathrm{~mL} \cdot \mathrm{s}^{-1}$. By using a three-way valve, sampling of the exhaled air occurred between the mask and the shutter system, at immediate proximity to the mask. The effective dead space consisted mainly of the mask $(10 \mathrm{~mL})$. FeNO was measured from the end-expiratory sample by using the plateau phase of the NO profile. Repeated exhalations were performed in order to obtain three reproducible FeNO measurements (variation $<10 \%$, maximum of $5 \mathrm{ppb}$ ). The mean value of these measurements was recorded as well as the ambient $\mathrm{NO}(\mathrm{NOamb})$ during the test.
Only measurements with NOamb $\leqslant 5$ ppb $(83 \%$ of the measurements) were included in the analyses.

\section{Lung function tests and the dosimetric methacholine challenge}

Lung function tests and the dosimetric methacholine challenge were performed according to the protocols used in our hospital [8]. All infants were studied when they were free from signs of acute respiratory infection, and $\beta 2$-agonists were withheld for $12 \mathrm{~h}$ prior to lung function and challenge tests. In brief, during lung function testing, the sedated infant was lying supine with the head supported in the midline and the neck slightly extended to minimise airway or glottic obstruction. All measurements were recorded and calculations performed with commercial paediatric pulmonary function equipment (MasterScreen ${ }^{\mathrm{TM}}$ BabyBody; Erich Jaeger $\mathrm{GmbH}$, Würtzburg, Germany). Functional residual capacity (FRC) was measured by whole body plethysmography. The maximal partial expiratory flow volume (PEFV) was obtained using the rapid thoracic compression technique (i.e. tidal squeeze) by rapid inflation of a thoracoabdominal jacket at the beginning of expiration. Flow was measured at the infant's nose and mouth with a pneumotachometer attached to a face mask. The compression pressure was progressively increased until there was no further increase in forced expiratory flow at FRC ( $V^{\prime}$ max,FRC), and the mean $V^{\prime}$ max,FRC of three technically acceptable PEFV curves obtained at that compression pressure was recorded. The baseline lung function results were expressed as z-scores, which are equivalent to the number of standard deviations by which the measured value deviates from the height- and sex-corrected reference value.

For the dosimetric methacholine challenge, a calibrated nebuliser (Salter Labs 8900, Arvin, CA, USA) was connected to an automatic, inhalation-synchronised dosimeter (Spira Electro II; Spira Respiratory Care Center Ltd, Helsinki, Finland). The dosimeter was set to be triggered by an inhaled volume of $20 \mathrm{~mL}$, after which a methacholine chloride dose of $50 \mu \mathrm{g}$ was nebulised within $0.2 \mathrm{~s}$ in an air volume of $25 \mathrm{~mL}$ in each breath. By calculating the number of breaths with nebulised methacholine, a rapid dosage scheme with four non-cumulative dose steps was applied $(0.1,0.3,0.9$ and $1.8 \mathrm{mg})$, with $V^{\prime}$ max,FRC being recorded after each dose. At each phase, the applied compression pressure was the same as that achieved in the highest flows at baseline. The provocative dose of methacholine causing a $40 \%$ fall in $V^{\prime}$ max,FRC (PD40 $V^{\prime}$ max,FRC) was determined from the dose-response curves. In cases where the maximal dose was reached and PD40 $V^{\prime}$ max,FRC could not be determined from the dose-response curves, for statistical purposes, PD40 V'max,FRC was defined as twice the highest dose of methacholine $3.60 \mathrm{mg}$.

During lung function measurements and the challenge test, oxygen saturation and heart rate were continuously monitored with a pulse oximeter. Following the challenge test, the children received inhaled salbutamol $(0.6 \mathrm{mg}$; Ventoline Evohaler $0.1 \mathrm{mg}$ per dose) via Nebunette (AstraZeneca Liquid production, Lund, Sweden) and the measurement of $V^{\prime}$ max,FRC was repeated 15 min after the salbutamol inhalation.

\section{Skin-prick tests}

Sensitisation to common food and/or inhalant allergens, including: egg white, cow's milk, wheat, soy bean, cod, shrimp, 
peanut, birch pollen, timothy grass pollen, dog epithelial dander, cat epithelial dander, and house dust mite Dermatophagoides pteronyssinus, was tested by SPTs. A positive SPT was defined as a wheal with a diameter of $\geqslant 3 \mathrm{~mm}$ against at least one of the tested allergens [21]. Physiologic saline was applied as a negative control.

\section{Definitions}

Food allergy was defined as a diagnosis confirmed by a positive food challenge. Atopic eczema was defined as a current diagnosis made by a paediatrician or a dermatologist. Atopy was defined as the presence of atopic eczema and/or a positive SPT. A parental history of asthma or allergy was defined as physician-diagnosed asthma or allergy, respectively, in either of the parents. A maternal history of asthma or allergy was defined as physiciandiagnosed asthma or allergy, respectively, in the mother of the child. Blood eosinophilia was defined as eosinophils accounting for $\geqslant 4 \%$ of the total white blood cells [22].

Lung function parameters that were regarded as abnormal had an FRC $z$-score of $\geqslant 2$ [8], and $V^{\prime}$ max,FRC $z$-score of $\leqslant-2$ [8]. FeNO values of $\geqslant 27 \mathrm{ppb}$, i.e. highest quartile, were considered elevated. PD40 $V^{\prime}$ max,FRC $\leqslant 0.30 \mathrm{mg}$ was considered as increased airway responsiveness to methacholine, PD40 V'max,FRC 0.31$0.90 \mathrm{mg}$ as intermediate responsiveness to methacholine, and PD40 $V^{\prime}$ max,FRC $\geqslant 0.91 \mathrm{mg}$ as no/mild responsiveness to methacholine.

\section{Statistics}

To evaluate the statistical differences between the groups, Chisquared test or Fisher's exact test (if the expected frequency for any cell was $<5$ ) were used to analyse categorical data, and Kruskal-Wallis test or Mann-Whitney U-test were applied to analyse continuous data. Correlations between continuous variables were determined by Spearman's rank correlation test. Logistic regression analysis was performed to calculate the adjusted odds ratios and related $95 \%$ confidence intervals in a multivariate setting, as follows: a dichotomous variable indicating elevated FeNO was included in the analysis as a dependent variable, and explanatory (those with $\mathrm{p}<0.05$ in univariate analyses) or confounding variables (selected by clinical importance, i.e. atopy and height) were included as covariates. All covariates were simultaneously added in the multivariate model. Two-tailed tests were used in all analyses. p-values $<0.05$ were considered statistically significant. The data were analysed using IBM SPSS 19.0 for Windows.

\section{RESULTS}

The median (range) age of the children studied was 16.4 months (4.0-26.7 months), and the median (range) height $80.7 \mathrm{~cm} \mathrm{(62.0-}$ $94.2 \mathrm{~cm}$ ). None of the children had major congenital cardiac or other malformations.

The median (range) duration of recurrent lower respiratory tract symptoms was 7 months (2-26 months), and cough was most commonly $(72 \%)$ reported as a main respiratory symptom. However, up to 105 (77\%) of the children had experienced at least one episode of wheezing confirmed by a physician. A parental history of asthma or allergy was present in 107 (79\%) children; in the majority $(60 \%)$, this was a maternal history of asthma or allergy. 57 (42\%) children had either atopic eczema, food allergy, and/or a positive SPT. Blood eosinophilia was present in $31(23 \%)$ children.

The median FeNO was $19.3 \mathrm{ppb}$ (IQR 12.3-26.9 ppb). The median (range) FRC z-score was $0.7(-2.2-4.8)$, and the median (range) $V^{\prime} \max$, FRC z-score -0.8(-3.8-1.5). FRC was regarded as abnormal in $27(20 \%)$, and $V^{\prime} \max , \mathrm{FRC}$ in $23(17 \%)$ children. Median coefficients of variation for FeNO, FRC, and $V^{\prime}$ max,FRC were $7 \%, 3 \%$, and $4 \%$, respectively. During the methacholine provocation, the median changes $V^{\prime} \max , \mathrm{FRC}$ and oxygen saturation were $-53 \%$ and $-3 \%$, respectively. $43(32 \%)$ children were found to have increased airway responsiveness to methacholine (i.e. PD40 $V^{\prime} \max , \mathrm{FRC} \leqslant 0.30 \mathrm{mg}$ ).

When the relationships between FeNO and baseline parameters were assessed, we found no correlation with age $\left(r_{s}=0.114\right.$, $p=0.188)$, height $\left(r_{s}=0.148, p=0.087\right)$, or percentage of eosinophils in peripheral blood $\left(\mathrm{r}_{\mathrm{s}}=-0.052, \mathrm{p}=0.583\right)$ (fig. 1), and no association between elevated FeNO (i.e. FeNO of $\geqslant 27 \mathrm{ppb}$ ) and blood eosinophilia (i.e. eosinophils $\geqslant 4 \%$ in peripheral blood) $(p=0.140)$. When associations between elevated FeNO and baseline characteristics were evaluated, a significant association between elevated FeNO and a maternal history of asthma was found (table 1). However, there were no other statistically significant associations between elevated FeNO and any other baseline characteristics in univariate analyses.

When lung function and methacholine challenge data were evaluated with regard to $F$ eNO, we found no correlations between FeNO and FRC $\left(\mathrm{r}_{\mathrm{s}}=-0.121, \mathrm{p}=0.163\right)$, or between FeNO and $V^{\prime} \max , F R C\left(r_{s}=-0.083, p=0.339\right)$. When analysed as a continuous variable, FeNO was not associated with airway responsiveness to methacholine (fig. 2). However, there was an association between elevated $\mathrm{FeNO}$ and increased airway responsiveness (fig. 3).

Finally, by performing multivariate logistic regression analysis, we were able to show that adjustment for the clinically most important confounding factors, i.e. atopy and height, did not

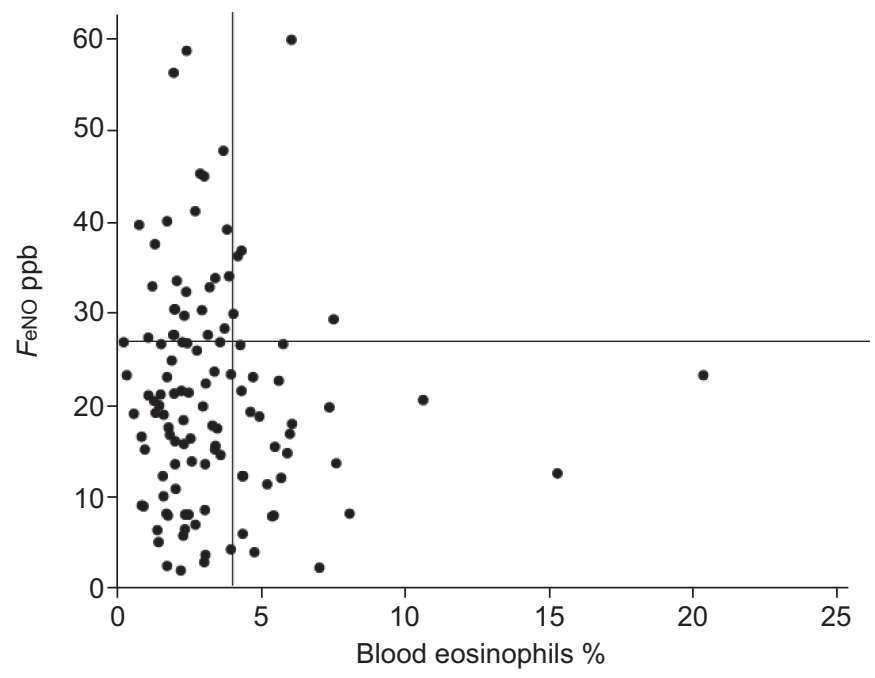

FIGURE 1. Exhaled nitric oxide fraction ( $F$ eNO) in relation to the percentage of blood eosinophils of the total white blood cells. No correlation was found between FeNO and the percentage of blood eosinophils $(p=0.583)$. In addition, there was no association between elevated FeNO (i.e. $\geqslant 27 \mathrm{ppb}$, horizontal line) and blood eosinophilia (i.e. $\geqslant 4 \%$, vertical line) $(p=0.140)$. 


\begin{tabular}{|c|c|c|c|}
\hline \multirow[t]{2}{*}{ Baseline characteristics } & \multicolumn{2}{|c|}{ FeNO } & \multirow[t]{2}{*}{ p-value ${ }^{\#}$} \\
\hline & $<27 \mathrm{ppb}$ & $\geqslant 27 \mathrm{ppb}$ & \\
\hline Subjects & 104 & 32 & \\
\hline Male/female & $74(71) / 30(29)$ & $23(72) / 9(28)$ & 0.937 \\
\hline \multicolumn{4}{|l|}{ History of asthma } \\
\hline Parental & $40(38)$ & $16(50)$ & 0.246 \\
\hline Maternal & $23(22)$ & $14(44)$ & 0.016 \\
\hline \multicolumn{4}{|l|}{ History of allergy } \\
\hline Parental & $77(74)$ & $25(78)$ & 0.641 \\
\hline Maternal & $61(59)$ & $17(53)$ & 0.580 \\
\hline Exposure to ETS & $34(33)$ & $9(28)$ & 0.604 \\
\hline Furry animals at home & $31(30)$ & $10(31)$ & 0.876 \\
\hline Atopic eczema & $28(27)$ & $4(13)$ & 0.093 \\
\hline Skin-prick test positive & $27 / 102(26)$ & $7(22)$ & 0.602 \\
\hline Atopy & $41(39)$ & $8(25)$ & 0.137 \\
\hline Food allergy & $25(24)$ & $7(22)$ & 0.801 \\
\hline \multicolumn{4}{|l|}{$\begin{array}{l}\text { Parentally reported main } \\
\text { respiratory symptom }\end{array}$} \\
\hline Dry cough & $57(55)$ & $16(50)$ & 0.633 \\
\hline Productive cough & $20(19)$ & $5(16)$ & 0.645 \\
\hline Wheeze & $14(13)$ & $5(16)$ & 0.774 \\
\hline Shortness of breath & $13(13)$ & $6(19)$ & 0.389 \\
\hline $\begin{array}{l}\text { Physician-confirmed } \\
\text { wheeze }\end{array}$ & $79(76)$ & $26(81)$ & 0.533 \\
\hline
\end{tabular}

Data are presented as $n$ or $n(\%)$, unless otherwise stated. Results are from the univariate analyses. ETS: environmental tobacco smoke. ${ }^{*}$ : analyses were performed using Chi-squared test or Fisher's exact test.

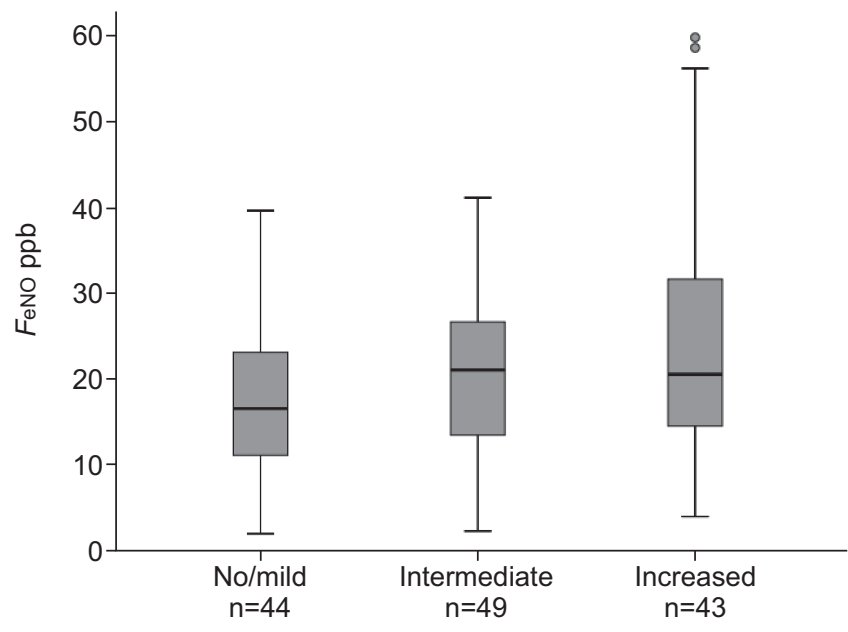

Airway responsiveness to methacholine

FIGURE 2. Exhaled nitric oxide fraction (FeNO) and airway responsiveness to methacholine. The range of $F_{e N O}$ was wide in all three levels of airway responsiveness, and no statistically significant associations were observed between $F_{e N O}$ and airway responsiveness $(p=0.165)$. The circles reprecent outliers.

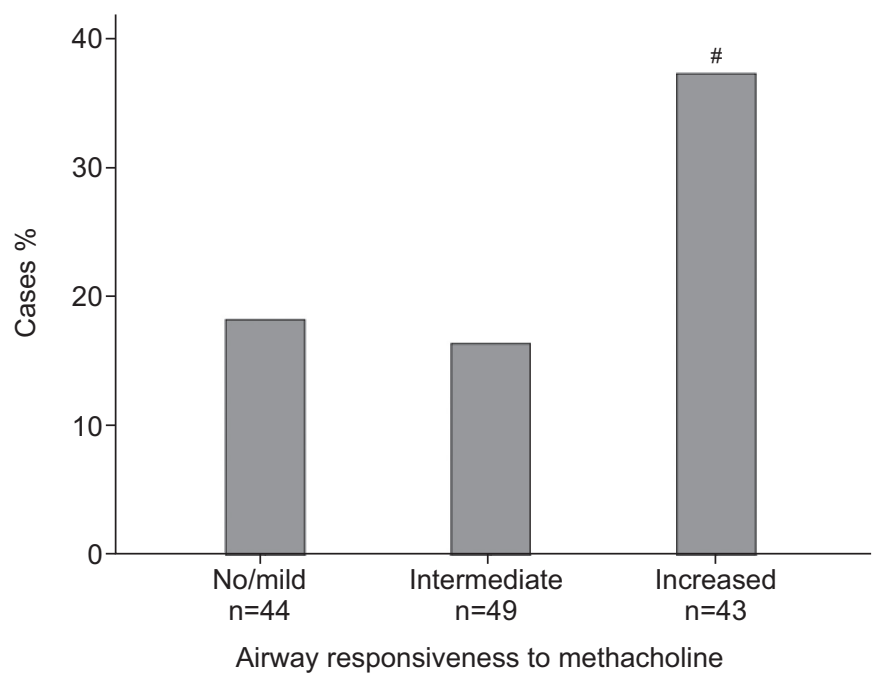

FIGURE 3. Cases of elevated exhaled nitric oxide fraction ( $F$ eNO) (i.e. $\geqslant 27 \mathrm{ppb}$ ) with regard to airway responsiveness. Increased airway responsiveness to methacholine (i.e. the provocative dose of methacholine causing a $40 \%$ fall in maximal expiratory flow at functional residual capacity (PD40 V'max,FRC) $\leqslant 0.30 \mathrm{mg}$ ) was associated with elevated FeNO when compared with no/mild airway responsiveness to methacholine (i.e. PD40 V'max,FRC $\geqslant 0.91 \mathrm{mg}$ ). ${ }^{*}$ : $p=0.047$.

change the significant results obtained in the univariate analyses. Both the maternal history of asthma and increased airway responsiveness were found to be independently associated with elevated FeNO (table 2).

\section{DISCUSSION}

In infants with recurrent lower respiratory tract symptoms, elevated FeNO was associated with a maternal history of asthma, and with increased airway responsiveness to methacholine. In contrast, no associations were found between elevated FeNO and age, height, sex, atopic manifestations, blood eosinophilia, paternal history of asthma or allergy, parentally reported respiratory symptoms, physician-confirmed wheeze, environmental exposures, or lung function.

TABLE 2 Baseline characteristics and factors with regard to elevated exhaled nitric oxide fraction $(\geqslant 27 \mathrm{ppb})$

\begin{tabular}{lcc} 
Parameter & OR $\left(\mathbf{9 5 \%} \mathbf{C l}^{\#}\right)$ & p-value ${ }^{\#}$ \\
\hline Maternal history of asthma & $3.2(1.3-8.1)$ & 0.012 \\
Atopy & $0.4(0.1-1.1)$ & 0.064 \\
Height & $1.0(1.0-1.1)$ & 0.252 \\
Airway responsiveness to methacholine & & \\
$\quad$ Increased & $4.1(1.4-12.7)$ & 0.012 \\
$\quad$ Intermediate & $1.4(0.4-4.7)$ & 0.547 \\
$\quad$ No/mild & 1.0 & \\
\hline \multicolumn{2}{c}{} \\
\hline
\end{tabular}

Results of the multivariate logistic regression analysis. OR: odds ratio; $95 \% \mathrm{Cl}$ 95\% confidence interval; ${ }^{*}$ : adjusted for the maternal history of asthma, atopy, height, and airway responsiveness to methacholine. 
In earlier studies, the relationship between increased airway responsiveness and $\mathrm{FeNO}$ has been controversial in school children. As regards online FeNO measurements, there are reports with no correlation between airway responsiveness and FeNO values [23, 24], as well as reports on the association between $F$ eNO and increased airway responsiveness to methacholine [3], histamine [2], and acetylcholine chloride [4]. Studies on infants are scarce: in a study on the relationship of FeNO and airway responsiveness in infants with eczema, there was a correlation between FeNO and increased airway responsiveness to methacholine [9].

At pre-school age, FeNO seemed superior to baseline respiratory function and bronchodilator responsiveness in identifying children with probable asthma in our earlier study [5]. In wheezy infants, anti-inflammatory therapy has been shown to reduce levels of FeNO [25-27]. Whether FeNO plays any role as a predictor of later childhood asthma in symptomatic infants is not known. In recently published studies, elevated FeNO predicted decline in lung function in infants with recurrent wheezing [28], and risk of future wheezing both in healthy neonates [29] and wheezy infants [28], although no correlation was found between FeNO and lung function measures at baseline [28, 29]. In line with recent findings, we could not find any association between baseline lung function and FeNO levels. However, there was an association between increased airway responsiveness to methacholine and elevated $F$ eNO in infants with recurrent lower respiratory tract symptoms, regardless of atopy and height.

Parental asthma is a well-known risk factor for asthma in offspring [22], and reduced lung function has been found in children with prolonged breastfeeding with asthmatic and atopic mothers [30]. As well, the maternal history of asthma or atopy has been reported to modify FeNO levels in certain selected cohorts of infants $[9,17]$, that is consistent with our finding on the association between elevated FeNO and a maternal history of asthma. It has been speculated that the milk of asthmatic and/or atopic mothers may differ from the milk of nonasthmatic and/or nonatopic mothers with regard to immunologically active substances and affect the outcome [30]. However, the detailed mechanisms underlying the increased risk related to maternal asthma are still to be elucidated.

In adults and school children FeNO has been proposed as a surrogate marker of eosinophilic airway inflammation [1], and there are reports on the association between elevated FeNO and blood or sputum eosinophilia in school children [2, 3, 13, 31]. According to our previous findings, eosinophilic airway inflammation is rarely seen in infancy $[6,7]$. However, during infancy the airways and lungs are in the process of growth and, among other factors, NO has various functions in the maturating lung [32]. In older subjects, changing expression of inducible NO synthase (NOS) is thought to explain exhaled NO variability, whereas in infancy, constitutional NO synthases may also contribute to exhaled NO concentrations [32]. In a recent article on normative data for exhaled NO in healthy infants [33], an upper limit for normal exhaled $\mathrm{NO}$ was determined as $26.1 \mathrm{ppb}$. In line with that, FeNO level of $\geqslant 27 \mathrm{ppb}$ was regarded elevated in symptomatic infants in the present study. However, we could not find a correlation between elevated FeNO and blood eosinophilia, and we presume that in infants with recurrent lower respiratory tract symptoms, elevated FeNO may rather reflect other aetiology than eosinophilic airway inflammation. In asthmatic subjects, certain viruses, e.g. rhinoviruses, have been found to increase production of exhaled NO by activating inducible NOS in the airways, and to induce airway hyperresponsiveness simultaneously [34]. Currently there are a lack of studies on the relationship of specific viral infections and FeNO levels in infants. Nevertheless, it has been postulated that there might be a causal relationship between recurrent lower respiratory tract symptoms in infancy, development of increased airway responsiveness, and airways inflammation later in childhood [35].

The clinical usefulness of FeNO in infants and older children has been hampered by several characteristics that have been pointed out to influence FeNO values: i.e. used methods [10], height [2], presence of atopic eczema [11, 12], skin-test reactivity $[2,3,7,12,13]$, acute respiratory symptoms [14-16], and tobacco smoke exposure [16-18]. In the present study, the used method for FeNO measurement mimics the single breath online method used in older children and adults by standardising the betweensubjects variation in tidal flow. However, the results are not directly comparable with those obtained by using the raised volume thoracoabdominal compression technique [10], due to different lung volumes at which the measurement occurs. The FeNO levels may also be confounded with NOamb [36], and in order to avoid that effect, cases with measurements of NOamb $>5 \mathrm{ppb}$ were excluded from the analyses. To eliminate the effect of acute respiratory infection to FeNO values, we excluded subjects with acute respiratory illness symptoms within the past 2 weeks from the final analyses. Because of avoiding performing methacholine challenge test in children with clinically evident bronchial obstruction, excluded children had more often abnormal results in baseline lung function measured by rapid thoracic compression technique. However, there were no differences in FeNO levels between included and excluded children.

As the children in the study represented the child population that had been referred to a university hospital clinic because of the recurrent symptoms, there was no selection based on certain respiratory symptoms or severity of symptoms, rendering the study population heterogeneous. However, our goal was not to compare FeNO in children representing different clinical entities, but to evaluate the association between FeNO and airway responsiveness in symptomatic infants, and such a study design does not necessitate symptom-based selection. As the study subjects were selected by their recurrent lower respiratory tract symptoms, the result could have been different if the study subjects had been compared with non-selected healthy children. For ethical reasons, it was not possible to recruit healthy children for such extensive investigations requiring sedation, and consequently we needed to perform all analyses within the study group.

In conclusion, in infants with recurrent lower respiratory tract symptoms, elevated FeNO values are related to increased airway responsiveness and to the maternal history of asthma. These findings may have implications in clinical practice when therapeutic measures are considered for infants with recurrent lower respiratory tract symptoms. In future, studies in symptomatic infants evaluating $F \mathrm{eNO}$ as a predictor of later childhood asthma would clarify whether FeNO will be suitable as a biomarker for monitoring early childhood wheezing illnesses. 


\section{SUPPORT STATEMENT}

The study was supported by Helsinki University Central Hospital Research Funds, Sigrid Juselius Foundation, and Finnish Allergy Research Foundation.

\section{STATEMENT OF INTEREST}

A statement of interest for the study itself can be found at www.erj. ersjournals.com/site/misc/statements.xhtml

\section{ACKNOWLEDGEMENTS}

We wish to thank registered nurses T. Rito and H. Punkari (both Dept of Allergology, Helsinki University Central Hospital, Helsinki, Finland) for their skill and care with the infants and their parents. The personnel of Spira Respiratory Care Center Ltd (Helsinki, Finland) is acknowledged for their help in the development of the inhalation-synchronised dosimetric equipment used in the methacholine challenge.

\section{REFERENCES}

1 Taylor DR, Pijnenburg MW, Smith AD, et al. Exhaled nitric oxide measurements: clinical application and interpretation. Thorax 2006; 61: 817-827.

2 Franklin PJ, Turner SW, Le Souëf PN, et al. Exhaled nitric oxide and asthma: complex interactions between atopy, airway responsiveness, and symptoms in a community population of children. Thorax 2003; 58: 1048-1052.

3 Strunk RC, Szefler SJ, Phillips BR, et al. Relationship of exhaled nitric oxide to clinical and inflammatory markers of persistent asthma in children. J Allergy Clin Immunol 2003; 112: 883-892.

4 Motomura $\mathrm{C}$, Odajima $\mathrm{H}$, Tezuka $\mathrm{J}$, et al. Effect of age on relationship between exhaled nitric oxide and airway hyperresponsiveness in asthmatic children. Chest 2009; 136: 519-525.

5 Malmberg LP, Pelkonen AS, Haahtela T, et al. Exhaled nitric oxide rather than lung function distinguishes preschool children with probable asthma. Thorax 2003; 58: 494-499.

6 Saglani S, Malmström K, Pelkonen AS, et al. Airway remodelling and inflammation in symptomatic infants with reversible airflow obstruction. Am J Respir Crit Care Med 2005; 171: 722-727.

7 Malmberg LP, Malmström K, Kotaniemi-Syrjänen A, et al. Does tidal exhaled nitric oxide reflect mucosal airway inflammation in infants? Thorax 2010; 65: 1027.

8 Kotaniemi-Syrjänen A, Malmberg LP, Pelkonen AS, et al. Airway responsiveness: associated features in infants with recurrent respiratory symptoms. Eur Respir J 2007; 30: 1150-1157.

9 Tepper RS, Llapur CJ, Jones MH, et al. Expired nitric oxide and airway reactivity in infants at risk for asthma. J Allergy Clin Immunol 2008; 122: 760-765.

10 Franklin PJ, Turner SW, Mutch RC, et al. Comparison of singlebreath and tidal breathing exhaled nitric oxide levels in infants. Eur Respir J 2004; 23: 369-372.

11 Dinakar C, Craff M, Laskowski D. Infants and toddlers without asthma with eczema have elevated exhaled nitric oxide levels. J Allergy Clin Immunol 2006; 117: 212-213.

12 Sonnappa S, Bastardo CM, Wade A, et al. Symptom-pattern phenotype and pulmonary function in preschool wheezers. J Allergy Clin Immunol 2010; 126: 519-526.

13 Thomas PS, Gibson PG, Wang H, et al. The relationship of exhaled nitric oxide to airway inflammation and responsiveness in children. J Asthma 2005; 42: 291-295.

14 Ratjen F, Kavuk I, Gärtig S, et al. Airway nitric oxide in infants with acute wheezy bronchitis. Pediatr Allergy Immunol 2000; 11: 230-235.

15 Franklin PJ, Turner SW, Hall GL, et al. Exhaled nitric oxide is reduced in infants with rhinorrhea. Pediatr Pulmonol 2005; 39: 117-119.
16 Gabriele C, Asgarali R, Jaddoe VW, et al. Smoke exposure, airway symptoms and exhaled nitric oxide in infants: the Generation $\mathrm{R}$ study. Eur Respir J 2008; 32: 307-313.

17 Frey U, Kuehni C, Roiha $\mathrm{H}$, et al. Maternal atopic disease modifies effects of prenatal risk factors on exhaled nitric oxide in infants. Am J Respir Crit Care Med 2004; 170: 260-265.

18 Franklin PJ, Turner S, Mutch R, et al. Parental smoking increases exhaled nitric oxide in young children. Eur Respir J 2006; 28: 730-733.

19 Kotaniemi-Syrjänen A, Malmberg P, Malmström K, et al. Factors associated with elevated $F$ eNO in infants with recurrent respiratory symptoms. Eur Respir J 2011; 38: Suppl. 55, 603s.

20 American Thoracic Society, European Respiratory Society. ATS/ ERS recommendations for standardized procedures for the online and offline measurement of exhaled lower respiratory nitric oxide and nasal nitric oxide, 2005. Am J Respir Crit Care Med 2005; 171: 912-930.

21 Dreborg S, Frew A. Position paper: allergen standardization and skin tests. Allergy 1993; 48: Suppl. s14, 48-82.

22 Castro-Rodríguez JA, Holberg CJ, Wright AL, et al. A clinical index to define risk of asthma in young children with recurrent wheezing. Am J Respir Crit Care Med 2000; 162: 1403-1406.

23 Silvestri M, Spallarossa D, Battistini E, et al. Dissociation between exhaled nitric oxide and hyperresponsiveness in children with mild intermittent asthma. Thorax 2000; 55: 484-488.

24 Miraglia del Giudice M, Brunese FP, Piacentini GL, et al. Fractional exhaled nitric oxide $(F \mathrm{eNO})$, lung function and airway hyperresponsiveness in naïve atopic asthmatic children. J Asthma 2004; 41: 753-759.

25 Baraldi E, Dario C, Ongaro R, et al. Exhaled nitric oxide concentrations during treatment of wheezing exacerbation in infants and young children. Am J Respir Crit Care Med 1999; 159: 1284-1288.

26 Moeller A, Franklin P, Hall GL, et al. Inhaled fluticasone dipropionate decreases levels of nitric oxide in recurrently wheezy infants. Pediatr Pulmonol 2004; 38: 250-255.

27 Straub DA, Moeller A, Minocchieri, et al. The effect of montelukast on lung function and exhaled nitric oxide in infants with early childhood asthma. Eur Respir J 2005; 25: 289-294.

28 Debley JS, Stamey DC, Cochrane ES, et al. Exhaled nitric oxide, lung function, and exacerbations in wheezy infants and toddlers. J Allergy Clin Immunol 2010; 125: 1228-1234.

29 Chawes BLK, Buchvald F, Bischoff AL, et al. Elevated exhaled nitric oxide in high-risk neonates precedes transient early but not persistent wheeze. Am J Respir Crit Care Med 2010; 182: 138-142.

30 Guilbert TW, Stern DA, Morgan WJ, et al. Effect of breastfeeding on lung function in childhood and modulation by maternal asthma and atopy. Am J Respir Crit Care Med 2007; 176: 843-848.

31 Steerenberg PA, Janssen NAH, de Meer G, et al. Relationship between exhaled NO, respiratory symptoms, lung function, bronchial hyperresponsiveness., and blood eosinophilia in school children. Thorax 2003; 58: 242-245.

32 Singer F, Latzin P. Exhaled nitric oxide in infants: a marker of inflammation? Eur Respir Monogr 2010; 49: 56-70.

33 Fuchs $\mathrm{O}$, Latzin $\mathrm{P}$, Thamrin $\mathrm{C}$, et al. Normative data for lung function and exhaled nitric oxide in unsedated healthy infants. Eur Respir J 2011; 37: 1208-1216.

34 de Gouw HWFM, Grünberg K, Schot R, et al. Relationship between exhaled nitric oxide and airway hyperresponsiveness following experimental rhinovirus infection in asthmatic subjects. Eur Respir J 1998; 11: 126-132.

35 Saglani S, Payne DN, Zhu J, et al. Early detection of airway wall remodeling and eosinophilic inflammation in preschool wheezers. Am J Respir Crit Care Med 2007; 176: 858-864.

36 Baraldi E, de Jongste JC. Measurement of exhaled nitric oxide in children, 2001. Eur Respir J 2002; 20: 223-237. 